\title{
PENGGUNAAN BAHASA DALAM RANAH PARIWISATA; STUDI DI KAWASAN TAMAN NASIONAL BANTIMURUNG BULUSARAUNG MAROS, SULAWESI SELATAN
}

\author{
Andi Samsu Rijal* \\ *Dosen pada Program Studi Sastra Inggris, Universitas Islam Makassar, Makassar, Indonesia \\ e-mail: andisamsurijal.dty@uim-makassar.ac.id
}

\begin{abstract}
The existence of tourism in the community provides an opportunity for the use of various language domains. The use of language by tour guides in National Park of Bantimurung Bulusaraung, Maros Regency, which is a Bugis-Makassar ethnic community, now used not only the regional language domain, Indonesian language, but also the Makassar Malay language $(M M L)$ domain and the foreign language ( $F L)$ domain. The use of this language is not only influenced by linguistic aspects but also influenced by non-linguistic aspects such as participant factors, speech situations, speech topics, the speaker's sociocultural background and speech partners. This article described the forms and variations of language that arise from language contact by guides and tourists. The research method used is a qualitative method with anthropological linguistic approach. Data collection was done by recording and semi-structured interviews with several informants. From the research results found three language choices including single language variation (SLV), language code switching (CS), and code mixing (CM). There were three uses of SL variations, namely Bugis Language (BL), Makassar Malay (MML) and Indonesian Language (I.L) formal varieties. The used of CS from both Bugis to Makassar language (ML) was also found in local tourists (Bugis speakers or Makassar speakers), CS from regional languages (RL) to MML also occurs in interactions between speakers and tourists or speech partners who are not Bugis-Makassar speakers but were the speaker of other regional languages in South Sulawesi. The used of CS from MML to Indonesian language had a formal variety of interactions with domestic tourists. Variations in English Makassar Malay Language as both CS and CM were found in interactions with foreign tourists.
\end{abstract}

Keywords:

Anthropological

Linguistics,

Language Choice,

Language Use,

Language Variation,

Tourism Aspects.

\section{LATAR BELAKANG}

Penggunaan bahasa di Taman Wisata Bantimurung Bulusaraung (Babul) Maros Sulawesi Selatan (Sul-Sel) terdapat tiga domain diantaranya bahasa Indonesia, bahasa daerah dan bahasa asing. Penggunaan domain bahasa tersebut terjadi karena adanya kontak bahasa dengan wisatawan baik wisatawan domestic maupun wisatawan asing. Berbagai variasi bahasa dalam komunikasi antara pramuwisata dan wisatawan di TN Babul Maros tersebut telah memunculkan fenomena wacana komunikasi yang sangat kompleks dan merupakan ciri khas sosiokultural masyarakat penutur. Atas penggunaan bahasa tersebut terjadi pilihan bahasa dan memunculkan identitas penutur dalam interaksinya dengan mitra tutur.

Sebagaimana diketahui bahwa dalam situasi diaglosik, penutur melakukan pilihan bahasa atas faktor mitra tutur, situasi tutur, tempat dan topik tuturan. Menurut Fishman, (1972) 


\section{SASDAYA,}

Gadjah Mada Journal of Humanities, Vol. 5. No. 1, 2021

bahwa pilihan bahasa masyarakat tutur tidak terjadi secara acak melainkan harus mempertimbangkan beberapa faktor seperti siapa berbicara, siapa lawan bicara, topik apa yang sedang dibicarakan dan dimana peristiwa tutur itu terjadi. Demikian halnya pramuwisata sebagai penutur dalam berkomunikasi dengan wisatawan melakukan berdasarkan situasi dan kepada siapa mereka berbicara, namun selain aspek tersebut tentu yang paling mempengaruhi dalam melakukan pilihan bahasa adalah faktor budaya partisipan. Sehingga dalam ranah pariwisata menjadi isu dalam artikel ini, guna mengungkap wujud dan faktor non linguistik yang mempengaruhi partisipan dalam menggunakan variasi bahasa tertentu.

Menurut Duranti, $(1997 ; 7)$ bahwa bahasa sebagai alat komunikasi sangat feksibel dan memiliki kekuatan secara intelektual dalam merefleksikan dunia, bahwa dengan bahasa pula dapat digunakan untuk mendeskripsikan bahasa itu sendiri. Pernyataan Duranti tersebut secara eksplisit bahwa dalam penggunaan bahasa dimana masyarakat memunculkan aspek sosiokultural mereka dalam berinteraksi termasuk pada situasi komunikasi dalam ranah pariwisata yang ada di TN Babul Maros. Bahasa sebagai identitas budaya penutur merefleksikan wujud kebudayaan dalam penggunaannya termasuk bentuk pilihan kode bahasa tertentu serta penggunaan variasi yang lahir dari interaksi masyarakat penggunaan bahasa. Fenomena kebahasaan pada interaksi pramuwisata dengan wisatawan merupakan situasi kebahasaan yang cukup menarik untuk dilakukan pengkajian secara mendalam. Situasi kebahasaan tersebut berbeda dengan situasi kebahasaan yang ada di pasar, di lingkungan keluarga, di kantor dan di lingkungan masyarakat secara umum yang hanya menggunakan domain bahasa daerah dan bahasa Indonesia. Dari hasil temuan Pelras, (1997; 13-14) dan Hasyim (2008) digambarkan bahwa dalam interaksi sosial masyarakat Sul-Sel sejak dahulu menggunakan suatu bahasa yang dapat diterima oleh keempat kelompok etnik ${ }^{1}$. Sementara penggunaan bahasa dalam ranah pariwisata di TN Babul Maros Sul-Sel terdapat tiga domain utama termasuk menggunakan domain bahasa asing, dan dalam penggunaannya tentu melahirkan variasi variasi bahasa tertentu dari adanya kontak bahasa serta adanya faktor budaya partisipan.

Penggunaan bahasa dalam ranah pariwisata yang dijumpai di kawasan TN Babul Maros menjadi bukti bahwa selain sebagai pintu masuknya bahasa asing juga menjadi transaksi budaya atas adanya kontak dengan wisatawan dari beragam etnik. Berbagai penggunaan variasi bahasa yang dijumpai pada situasi percakapan dalam ranah pariwisata di TN Babul seperti bahasa bugis (bB) dialek Maros², bahasa Makassar (bM)3 ${ }^{3}$, bahasa Melayu Makassar $(\mathrm{BMM})^{4}$ dan bahasa Inggris dialek Melayu Makassar (B.Ing MM) baik sebagai alih kode

${ }^{1}$ Masyarakat tutur Sul-Sel memiliki empat kelompok besar bahasa yaitu; bahasa Makassar dari etnik Makassar, bahasa Bugis dari etnik Bugis, bahasa Mandar etnik Mandar dan bahasa Toraja dari etnik Toraja.

2 Bahasa bugis adalah bahasa Austronesia yang dituturkan oleh masyarakat etnik Bugis seperti dari kabupaten Maros, Bone, Sidrap, Soppeng, Sinjai, Bulukumba, Barru, Pinrang, Pangkep dan beberapa daerah lainnya dengan jumlah penutur kurang lebih 5 juta. Adapun bahasa bugis dialek Maros adalah penggunaan bahasa bugis dengan penambahan kata/ prasa "Iyyo Lasso", "Eedende" yang bermakna penegas dalam kalimat, begitu juga "anu Do" juga bermakna pernyataan penegas.

${ }^{3}$ Bahasa Makassar adalah bahasa Austronesia yang dituturkan oleh masyarakat etnik Makassar dengan kurang lebih 2 juta penutur (https://id.wikipedia.org/wiki/Bahasa_Makassar)

${ }^{4}$ Bahasa Melayu Makassar adalah bahasa trade Malay, bahasa Indonesia dengan logat Makassar serta tambahan beberapa suku kat di akhir kata dasar seperti dimanaKI, ayoMI, dimanaKO, bukuTA (buku kamu). Kini bahasa Melayu Makassar merupakan lingua franca untuk wilayah Sulawesi dan Sekitarnya. 


\section{SASDAYA,}

Gadjah Mada Journal of Humanities, Vol. 5. No. 1, 2021

maupun campur kode. Penggunaan variasi tersebut muncul akibat adanya pemilihan kode bahasa tertentu yang terjadi dari interaksi penutur dengan mitra tutur yang setiap saat berbeda. Senada yang diungkapkan oleh Duranti, $(1997 ; 2)$ bahwa penutur dalam menggunakan kode bahasa sangat erat kaitannya dengan latar belakang sosial budaya masyarakat. Mengingat masyarakat DTW TN Babul Maros merupakan penutur bahasa bugis (bB) namun dalam interaksi sosial di masyarakat terlebih pada ranah pariwisata tidak konsisten dalam menggunakan bB bahkan sering terjadi pencampuran kode bahasa tertentu dan alih kode baik dari BB ke bahasa Makassar (BM) atau ke (BMM), sebaliknya dari BMM ke BM atau ke BB.

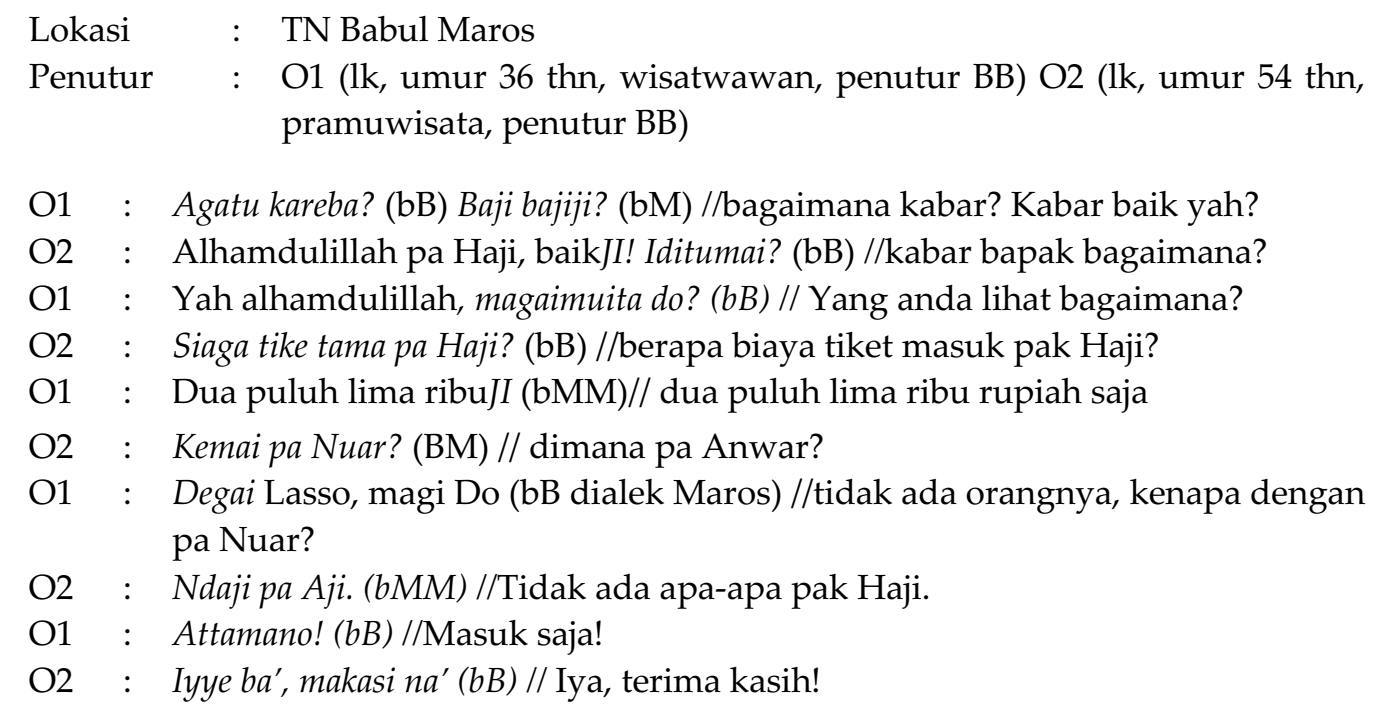

\section{Lokus 1}

Percakapan di atas seringkali dijumpai pada situasi tuturan masyarakat Maros termasuk di kawasan TN Babul Maros, O1 selaku penutur melakukan pilihan bahasa berdasarkan partisipan dan latar belakang sosial budaya mitra tutur. Dengan kemiripan budaya partisipan sehingga sangat mudah melakukan alih kode dari satu bahasa ke bahasa lainnya. Hal yang berbeda jika mitra tutur merupakan wisatawan domestik yang bukan penutur bugis-Makassar atau seseorang yang belum dikenal maka akan menggunakan bahasa Indonesia, begitu halnya jika mitra tutur merupakan wisatawan asing maka penutur menggunakan bahasa Inggris meski dengan dialek Melayu Makassar (B.Ing.MM).

Variasi Melayu Makassar pada penggunaan bahasa Indonesia dan bahasa Inggris yaitu adanya penambahan JI, TO', MI, TA, KI, dan dalam penggunaan bB dialek Maros yaitu adanya kata Lasso (Iyyo Lasso, Awasko Lasso) dan DO (Anu Do, mau ke mana Do) yang tidak memiliki arti tersendiri namun berfungsi sebagai penegas. Begitu juga dalam penggunaan variasi bMM dalam bahasa Inggris seperti pada dalam sapaan ke wisatawan asing; bagaimana kabarTA mister, siniki mister/ come hereLAH! JangKI malu-malu bro!, calling calling yah kalo ko kesini lagi ${ }^{5}$. Variasi melayu Makassar merupakan identitas budaya bagi penutur bugis-

\footnotetext{
${ }^{5}$ Penggunaan bahasa Inggris dialek Melayu Makassar yang digunakan oleh Pramuwisata TN Babul dalam situasi percakapan dengan wisatawan yaitu dengan penambahan kata/ phrasa di akhir kata/ kalimat seperti "come here LAH mister!", calling-calling yah kalo ko ke sini lagi
} 


\section{SASDAYA,}

Gadjah Mada Journal of Humanities, Vol. 5. No. 1, 2021

Makassar, dimana penggunaan bahasa tersebut dianggap sebagai sebuah kesopanan dalam bertutur dan terkadang mengandung unsur eufemisme ${ }^{6}$ (Rusdiah, 2016; Bachriani, Yassi, \& Rahman, 2018), dan hal berbeda dengan bB dialek Maros yang terkadang dianggap sebagai penegas negatif.

Dalam situasi percakapan bagi masyarakat dwibahasawan dan multibahasawan akan menggunakan pilihan bahasa yang tepat agar diterima oleh mitra tutur selama bahasa tersebut berfungsi sebagai lingua franca (Mondada, 2012). Penggunaan bahasa daerah dan bahasa Indonesia dalam ranah pariwisata yang digunakan oleh penutur berfungsi sebagai lingua franca local bagi mitra tutur yang merupakan wisatawan domestic, bahasa Inggris pun demikian akan berlaku sebagai lingua franca global bagi mitra tutur yang merupakan wisatawan asing. Masalah yang ingin diungkapkan dalam studi ini adalah bagaimana wujud variasi bahasa dan pilihan bahasa dalam ranah pariwisata di TN Babul Maros serta faktor-faktor yang mempengaruhinya.

Secara umum kajian atas penggunaan bahasa telah dilakukan oleh beberapa peneliti sebelumnya dalam ranah pariwisata diantaranya Beratha, (1999), Budiarsa \& Wijana, (2006), Fox, (2008); Setyanto, (2014); Sudana, (2014), Malini, Laksminy, \& Sulibra, (2018); Agung, Wati, Simpen, \& Arnati, (2018), Dhanawaty, (2020). Berbagai penggunaan variasi bahasa Inggris ditemukan oleh Beratha (1999) atas interaksi pramuwisata dengan wisatawan di Bali termasuk bahasa pidgin. Budiarsa (2006) juga telah mengamati situasi percakapan wisatawan pada beberapa hotel di Bali. Budiarsa menemukan adanya beragam variasi bahasa Indonesia, Bahasa Bali dan variasi bahasa Inggris, selain itu juga terdapat bentuk dan strategi komunikasi.

Kajian penggunaan bahasa secara umum juga telah dilakukan oleh beberapa peneliti dari luar dan juga di Indonesia, baik dalam ranah keluarga, di masyarakat umum, di ranah formal (di sekolah atau di kantor) seperti Goebel, (2007), Hasyim, (2008) Hanafia, (2011), Apriliyani \& Rokhman, (2016), Laiya, (2015), Muthmainnah, (2008), Niswa \& M. Mukhlish, (2017), Sudono, (2014), Sulastriana, (2017), Tamrin, (2013), Thomas \& Rustono, (2016), Wardhani, (2018), Widianto, (2016). Sebagaimana kajian etnografi Goebel atas dalam lingkungan Rukun Tetangga (RT) masyarakat perkotaan di Semarang Indonesia bahwa terdapat pola pertukaran simetris yang berlaku pada. Keakraban sesama etnik dan antar etnik serta sosial ekonomi turut mempengaruhi dalam kelangsungan komunikasi masyarakat perkotaan. Kajian Hasyim (2008) dan Tamrin (2013) atas kasus penggunaan bahasa bagi masyarakat etnik Makassar di Gowa dan etnik bugis yang ada di Sulawesi Tengah bahwa cenderung menggunakan bahasa daerah masing-masing sebagai bahasa utama, bahasa Indonesia sebagai bahasa kedua, dan bahasa melayu Makassar sebagai bahasa ke tiga atau berfungsi sebagai alih kode.

Tentu sesuatu hal yang berbeda dengan dalam ranah pariwisata yang cenderung berinteraksi dengan orang baru atau wisatawan maka akan mengedepankan asas tujuan komunikasi dan kemampuan linguistik dari mitra tutur. Sejauh ini kajian serupa terkait dalam ranah pariwisata di Sul-Sel masih minim sehingga dengan mengangkat fenomena linguistik dalam interaksi masyakat etnik Bugis-Makassar di Kabupaten Maros dengan wisatawan dapat menambah literatur baik dalam aspek linguistik; linguistik antropologi dan sosiolinguistik maupun keterkaitan linguistik dengan aspek kepariwisataan.

\footnotetext{
${ }^{6}$ Eufemisme adalah ungkapan ungkapan pemanis yang biasa ditemui dalam percakapan masyarakat Indonesia baik dalam bahasa daerah, bahasa Indonesia maupun dalam berbahasa asing
} 


\section{SASDAYA,}

Gadjah Mada Journal of Humanities, Vol. 5. No. 1, 2021

\section{LANDASAN TEORI}

Penggunaan suatu bahasa tergantung pada partisipan, situasi, topik dan tujuan pembicaraan. Sehingga partisipan yang kedudukannya berbeda akan digunakan bahasa yang berbeda, demikian pula untuk situasi resmi dan tidak resmi tentu membutuhkan kode yang berlainan (Chaer \& Agustina, 2004; 149). Pada masyarakat dwibahasan dan multibahasawan tersedia berbagai kode bahasa, variasi, dialek dan gaya bahasa yang memungkinkan penutur untuk melakukan pilihan bahasa dalam berinteraksi dengan masyarakat lainnya. Menurut Wardhaugh, $(2006,102)$ bahwa pada masyarakat multilingual seperti di Indonesia yang memiliki beragam bahasa seperti bahasa daerah, bahasa nasional dan juga bahasa asing maka cenderung memilih satu variasi bahasa (intralingual variation), memilih alih kode atau bahkan campur kode bahasa.

Menurut (Fasold, 1984) bahwa pilihan bahasa dapat dilakukan berdasarkan tiga pendekatan disiplin ilmu yaitu pendekatan sosiologi, pendekatan psikologi sosial dan pendekatan antropologi. Dari ketiga pendekatan tersebut yang paling dekat dengan situasi pada ranah pariwisata di Indonesia adalah pendekatan sosiologi. Dimana pendekatan sosiologi akan melihat adanya aspek konteks institusional tertentu seperti variasi bahasa tertentu lebih tepat digunakan dalam satu komunitas tutur dibanding variasi lainnya. Berbeda halnya dengan pandangan Chaer \& Agustina, $(2004 ; 149$, 153) bahwa kasus bukan hanya faktor sosiologi, psikologi sosial dan sosiologi melainkan adanya sikap bahasa masyarakat penutur. Sebab sikap bahasa dapat menentukan kelangsungan hidup suatu bahasa dan hal tersebut sangat terkait dengan pada masyarakat tutur.

Masyarakat sebagai komunitas tutur, menjadikan bahasa sebagai representasi dari bahasa itu sendiri dan representasi sosial budaya masyarakat. Para pakar sosiolinguistik seperti Holmes, Hymes, Labov dan Wardaugh (dalam Mohammad \& Al-harahsheh, 2015) telah menghubungkan antara penggunaan dan masyarakat sebagai fenomena sosial budaya. Tentang bagaimana bahasa diproduksi dan dikembangkan oleh individu melalui interaksi komunikasi budaya. Sebab komunitas tutur merupakan kelompok yang mewakili nilai nilai dan sikap tentang kegunaan bahasa, varian bahasa dan praktik dalam interaksinya di masyarakat.

Menurut Morgan, (2014) bahwa komunitas tutur telah menjadi interpretasi dan representasi terhadap masyarakat dan situasi yang ditandai dengan perubahan, perbedaan dan perkembangan teknologi sehingga berkembang terus menerus melalui interaksi yang berlangsung lama dalam masyarakat dengan sistem nilai yang ada. Mulai dari manusia dilahirkan dengan kemampuan untuk mempelajari bahasa, begitu halnya budaya dan masyarakat yang dibingkai dengan proses pembelajaran tentang bagaimana kita berinteraksi ke sesama manusia. Kerangka tersebut secara eksklusif berlangsung dengan interaksi antar individu dalam komunitas dengan latar belakang budaya dan bahasa yang sama. John Gumperz menggarisbawahi bahwa komunitas tutur tak lain sebagai konstruksi sosial, dan eksistensi suatu komunitas tutur ditandai dengan adanya interaksi tatap muka dan saling kontak bahasa seperti dalam situasi percakapan. Gumperz juga mengakui bahwa terkadang ada persamaan dan perbedaan variasi tutur dalam suatu komunitas tutur yang pada akhirnya terbentuk semacam system keteraturan karena mereka saling berinteraksi antar-individu guna membentuk system keteraturan yang diberlakukan dalam masyarakat (Morgan, 2014).

Berbeda dengan Hymes, (2013) yang tidak membatasi konsep komunitas tutur sebagai keterkaitan antara bahasa dan situasi sosial masyarakat atau adanya system keteraturan penggunaan bahasa, namun lebih pada konsep fundamental atas keterkaitan antara bahasa, 


\section{SASDAYA,}

Gadjah Mada Journal of Humanities, Vol. 5. No. 1, 2021

tutur, dan struktur sosial. Sehingga Hymes beranggapan bahwa definisi komunitas tutur bukanlah sesuatu definisi yang paten. Pada dasarnya Hymes melalui tawaran model komunikasi etnografinya mengingatkan atas pentingnya dalam hal penguasaan kompetensi komunikasi dan pengetahuan yang harus dimiliki bagi penutur agar dapat tergabung dalam komunitas tutur. Kompetensi komunikasi dimaksudkan sebagai kemampuan bagi penutur dalam penggunaan bahasa dan bersosialisasi dalam masyarakat, sehingga kompetensi komunikasi tak lain sebagai hubungan bahasa kode komunikasi yang digunakan dalam masyarakat (Morgan, 2014).

Grosjean, (2010) menegaskan bahwa pilihan bahasa didasari atas empat faktor yaitu partisipan, situasi, isi wacana dan fungsi interaksi (Malini dkk., 2018). Menurut Fasold, (1984) bahwa ketika seseorang berbicara tentang pilihan bahasa maka yang pertama dipikirkan adalah "Whole Language" yang ada dalam masyarakat multibudaya yang hidup beragam bahasa di dalamnya. Sehingga pilihan bahasa akan mungkin terjadi. Dalam kasus pilihan bahasa pada masyarakat multibudaya, Chaer \& Agustina, $(2004 ; 153,155)$ tidak membatasi dengan suatu batasan faktor internal dan eksternal. Bahkan Chaer dan Agustina menjelaskan bahwa pilihan bahasa dilakukan sebab adanya sikap bahasa. Sementara Duranti, (1997) menyederhanakan situasi yang kompleks hingga penggunaan suatu bahasa terjadi atas adanya kondisi budaya penutur dalam menggunakan bahasa dan secara tidak langsung penutur memunculkan budaya mereka melalui bahasa yang digunakan. Dalam konteks pilihan bahasa di Indonesia sendiri menurut Chaer dan Agustina $(2004 ; 154)$ bahwa terdapat tiga kategori pilihan bahasa yaitu bahasa Indonesia, bahasa daerah dan bahasa asing. Adapun jenis pilihan bahasa yang digambarkan baik Chaer \& Agustina (2004) dan Sumarsono (2017) yaitu pertama adanya penggunaan alih kode (AK), penggunaan campur kode (CK), dan memilih sa tu variasi bahasa yang sama.

\section{METODE PENELITIAN}

Bahasa sebagai suatu fenomena sosial sangat erat kaitannya dengan struktur dan nilai sosial masyarakat. Kajian dalam ranah pariwisata di kawasan TN Babul Maros Sul-Sel sangat erat kaitannya dengan latar belakang sosial budaya penutur serta faktor mitra tutur. Olehnya itu kajian ini menggunakan metode kualitatif dengan pendekatan linguistik antropologi. Secara teoritis kajian ini menggunakan pendekatan linguistik antropologi Duranti, (1997). Teknik penelitian yang digunakan adalah teknik observasi. Teknik observasi dengan teknik lanjutan yaitu perekaman percakapan pramuwisata dan wisatawan di TN Babul Maros. Data dalam penelitian ini diambil dari peristiwa tutur antara pramuwisata dan wisatawan di kawasan Taman Nasional Bantimurung Bulusaraung Kabupaten Maros. Sebagai penelitian field research dengan pendekatan linguistik antropologi bahwa terdapat sebuah proses penggambaran suatu fenomena kebahasaan serta masalah kemanusiaan dimana terdapat pengaruh budaya masayarakat yang turut serta mempengaruhi penggunaan bahasa masyarakat termasuk dalam hal pilihan bahasa.

Perekaman percakapan antara penutur dengan mitra tutur dilakukan dengan variasi pengambilan data berbeda yaitu bisa dilakukan perekaman langsung, video rekaman percakapan dengan atau tanpa seizin dari pramuwisata. Data yang diperoleh selanjutnya diidentifikasi, dan ditranskripsi secara tertulis kemudian dikelompokkan sesuai yang dilakukan oleh penutur dengan mitra tutur. Data yang dikumpulkan kemudian dilakukan analisis secara deskriptif dengan melihat wujud penggunaan pilihan bahasa dan identitas penutur. 


\title{
HASIL
}

Variasi bahasa pada peristiwa kontak bahasa di Sulawesi Selatan karena adanya beragam etnik dan bahasa maka membuat masyarakat Sul-Sel cenderung menggunakan pilihan bahasa berdasarkan situasi tutur dan partisipan. Namun selain itu bahwa beberapa daerah di Sul-Sel termasuk Maros merupakan daerah tujuan wisata nasional dan daerah tujuan wisata dunia karena atas panorama alam, bentangan bebatuan Karst, jejeran gua gua endemic, dan juga beragam fauna termasuk Monyet dan Kupu-kupu yang tidak ditemukan di daerah lainnya di Sul-Sel maupun di Sul-Sel. Hingga tahun 1857 Naturalist Alfred Russel Wallace menjuluki Taman Nasional Bantimurung sebagai the Kingdom of Butterfly ${ }^{7}$. Atas situasi dan tawaran pariwisata tersebut sehingga banyak wisatawan berkunjung ke Taman Nasional Bantimurung Bulusaraung Maros, maka sering terjadi kontak bahasa dan budaya di area pariwisata. sehingga dalam artikel ini akan mendeskripsikan wujud bahasa apa saja dalam pilihan bahasa yang digunakan oleh penutur dan faktor-faktor apa saja yang mempengaruhi pilihan bahasa bagi pramuwisata dalam situasi percakapan dengan wisatawan di kawasan TN Babul Maros.

Adapun wujud pilihan bahasa yang ditemukan dalam situasi percakapan antara penutur dan mitra tutur dalam ranah pariwisata yaitu terdapat tiga diantaranya penggunaan tunggal bahasa (TB), alih kode bahasa (AK), dan campur kode (CK). Penggunaan TB dapat dijumpai dalam situasi percakapan dimana partisipan menggunakan bahasa Bugis (BB) dan bahasa Melayu Makassar (BMM). Penggunaan TB bahasa Bugis terjadi pada saat komunikasi antara penutur di TN Babul Maros dengan mitra tutur yang berbahasa bugis pula. Dalam hal ini kedua partisipan sudah saling akrab satu sama lain dan situasi komunikasi yang tidak berlangsung lama misalnya mitra tutur sebagai wisatawan lokal yang hanya ingin menanyakan seseorang yang kemungkinan juga dikenal oleh penutur, menanyakan pengunjung, menanyakan kabar penutur, menanyakan harga tiket, atau merespon pertanyaan penutur yang sedang menggunakan BB. Penggunaan TB dengan variasi BMM terjadi jika penutur sedang dalam ranah formal misalnya ada kunjungan khusus, situasi mitra tutur yang nampak berseragam formal (ASN, Seragam Sekolah/kampus, TNI/POLRI).

Penggunaan AK dilakukan oleh penutur jika situasi komunikasi dengan wisatawan/ mitra tutur dwibahasawan, sudah saling akrab, AK diawali oleh mitra tutur dan jika penutur ingin menyampaikan sesuatu yang dianggap penting untuk diketahui oleh mitra tutur. Seperti pada situasi percakapan di bawah;

\author{
Lokasi : Taman Prasejarah \\ Penutur : O1: Pramuwisata, LK, 54, penutur BB \\ $\mathrm{O} 2$ : Wisatawan domestic, LK 36, penutur BB
}

O1

: Halo!

\footnotetext{
${ }^{7}$ Tahun 1857 Alfred Russel Wallace menjuluki TN Babul Maros sebagai kerajaan Kupu-Kupu dimana terdapat kurang lebih 250 jenis kupu-kupu, dan pada tahun 2019 TN Babul Maros masuk sebagai ASEAN Heritage Park (https:/travel.tempo.co/read/1265590/bantimurung), dan pada tahun 2020 masuk kategori GEOARK oleh UNESCO
} 


\section{SASDAYA,}

Gadjah Mada Journal of Humanities, Vol. 5. No. 1, 2021



\section{Lokus 2}

Percakapan tersebut berlangsung di Taman Prasejarah Leang-Leang Maros yang masuk juga sebagai kawasan Taman Nasional. Kedua penutur sudah saling akrab dan keduanya merupakan penutur BB. Sehingga dalam komunikasi sering terjadi alih kode dari BB ke BM, ke BI dan juga ke BMM. O1 menyapa dengan sapaan akrab, dan disambung oleh $\mathrm{O} 2$ dengan BB dan dijawab oleh O1 dengan BMM. O1 melanjutkan pembicaraan dengan menggunakan BB, kemudian O2 melakukan alih kode ke BI dan O1 menjawab dengan BM. Variasi BMM terjadi dalam komunikasi tersebut karena adanya faktor multibahasawan masing-masing penutur dan juga karena adanya faktor partisipan.

Sementara penggunaan variasi bahasa yang lain juga ditemukan dalam situasi percakapan antara pramuwisata dan wisatawan di TN Babul Maros yaitu variasi bahasa Inggris Melayu Makassar (B.Ing MM). Variasi B.Ing MM merupakan variasi yang berkembang di kota Makassar, baik kalangan pelajar, guru, dosen dan juga beberapa praktisi. Selain itu variasi B.Ing MM juga sering ditemukan bagi penutur bugis-Makassar jika berkomunikasi dalam bahasa Inggris dengan mitra tutur baik kepada native speaker maupun non-native.

1. [tomorrow-tomorrow comeback-lah mister, I pick you di, in airport, call, ok]

2. [many-many different mister, ini murah toh]

3. [Hei mister, I will join ke gua-nah]

Lokus 3

Dari data di atas menggambarkan bahwa variasi B.Ing MM lahir atas interferensi penutur dan faktor dialek BMM yang kerapkali digunakan dalam percakapan sehari hari. Seperti percakapan antara pemandu wisata, pemilik warung dan dua wisatawan asal Belanda pada salah satu rumah makan di dalam taman wisata karst Rammang-Rammang kabupaten Maros (2 November 2019). SN merupakan pramuwisata, BW adalah wisatawan Belanda (W, 52), BW wisatawan asal Belanda (M, 54), D. Ras (DTW, 55, penutur bugis).

\footnotetext{
SN : What do you think of the food, oo of the dinner oo you tou in in Nederland? (Seperti apa makanan malam Anda di Belanda?)

BW : The name is Banana, you know a! (Namanya pisang)
} 


\section{SASDAYA,}

Gadjah Mada Journal of Humanities, Vol. 5. No. 1, 2021

\begin{tabular}{|c|c|c|}
\hline SN & & $\begin{array}{l}\text { Because too sweet orrr? You know a.. (apakah karena cukup manis atau } \\
\text { bagaimana? }\end{array}$ \\
\hline BW & : & $\begin{array}{l}\text { This one I like because original, nice and unique food (makanan seperti ini saya } \\
\text { suku karena asli, enak dan tampaknya unik) }\end{array}$ \\
\hline D.Ras & : & Telur ayam, telur chicken tau bebek (pilihan menu lauk pauk) \\
\hline SN & & $\begin{array}{l}\text { Ini telur bebek, jelaskanngngi begitu.....Supaya belajarko bahasa Belanda (ini } \\
\text { telur bebek, silahkan dijelaskan dengan baik agar kamu juga bisa belajar } \\
\text { bahasa Belanda) }\end{array}$ \\
\hline SN & : & $\begin{array}{l}\text { Passui bahasamu daeng pa' rasi (bisa dipersilahkan dan dijelaskan dengan } \\
\text { bahasamu sendiri pa Rasi) }\end{array}$ \\
\hline D.Ras & : & $\begin{array}{l}\text { Perkedel jagung, chickin apakah?, ayam (yang ini perkedel jagung "gorengan } \\
\text { terbuat dari jagung", chicken apakah bahasanya? "ayam, sup" }\end{array}$ \\
\hline SN & : & Nasi tawwa ! Ayam goreng, sup, ikan, ikan salmon, telur, sambel \\
\hline D.Ras & : & Rice, nasi putih (nasi putih) \\
\hline B.L & : & Nasi putih? (makan sambil bertanya) \\
\hline SN & & $\begin{array}{l}\text { If you need more vegetable, rice and ..for full your stomach (jika nada butuh } \\
\text { menambah sayur, nasi dan ..untuk mengenyangkan perut Anda silahkan!) }\end{array}$ \\
\hline & & Ok (Oke) \\
\hline . $\mathrm{L}$ & & Thank you (Terima Kasih) \\
\hline
\end{tabular}

\section{Lokus 4}

Dalam konteks percakapan di atas melibatkan setidaknya empat orang penutur dalam suasana makan siang, dua diantaranya wisatawan asal Belanda dengan tujuan wisata ke taman wisata karst Rammang-Rammang, selebihnya adalah masyarakat DTW TN Babul dengan inisial SN dan D.Ras, mereka (SN dan D.Ras) adalah penutur Bugis, dan sering menggunakan BMM. SN sering melakukan interferensi seperti pengulangan kata 'oo' dalam percakapan, penggunaan kata 'or' dengan 'orrr' hal tersebut menandakan bahwa pada dasarnya menunggu respon dari mitra tutur. Sementara interferensi yang dilakukan oleh D.Ras adalah ketidakmampuan dalam menggunakan bahasa inggris dengan baik sehingga hanya mengkombinakasikan kosakata bahasa Indonesia dengan bahasa Inggris. Seperti [telur, ayam, chicken], \{rice, nasih putih, makanG-makanG]. Begitu juga SN dalam situasi tiga arah melakukan campur kode bahasa baik bahasa Indonesia dialek MM (BMM), bB, dan juga b.Ing MM demi untuk menjelaskan sesuatu baik kepada mitra tutur (wisatawan) maupun kepada rekan (D.Ras).

\section{PEMBAHASAN}

Masyarakat kabupaten Maros terbilang istimewa jika dibandingkan dengan masyarakat lainnya yang ada di Sulawesi Selatan, Barat, Tengah, Utara dan Tenggara. Selain sebagai daerah transisi antara kabupaten di Sulawesi Selatan, daerah penyangga ibu kota juga sebagai daerah tujuan wisata. Aspek lain yang dimiliki adalah adanya keanekaragaman bahasa yang dimiliki oleh masyarakatnya sebab dikenal dengan masyarakat etnis BugisMakassar, meski sebagai penutur bugis dengan dialek tersendiri namun dipastikan masyarakat Maros memahami bahasa Dentong dan bahasa Makassar terlebih bahasa Melayu Makassar yang lahir atas interaksi dengan masyarakat perbatasan di Sulawesi Selatan. Dengan kehadiran taman nasional yang saat ini menjadi wisata geopark (Disbudpar Maros, 2020), sehingga banyak diantara masyarakat Maros tergabung sebagai pramuwisata. 


\title{
SASDAYA,
}

Gadjah Mada Journal of Humanities, Vol. 5. No. 1, 2021

Sebagai pramuwisata yang kerapkali melakukan kontak bahasa dan budaya yang tidak hanya dengan kelompok etnis Sul-Sel namun juga di luar Sul-Sel seperti wisatawan domestic dan wisatawan mancanegara. Sehingga dalam interaksinya dengan wisatawan cenderung melakukan pilihan kode bahasa. Berdasarkan temuan penggunaan bahasa di atas bahwa terdapat penggunaan Tunggal Bahasa (TB), Alih Kode (AK), dan Campur Kode (CK). Penggunaan ketiga pilihan bahasa tersebut merupakan wujud dari identitas dan sosiokultural masyarakat. Sebagaimana dijelaskan oleh Duranti, $(1997 ; 1,2)$ bahwa bahasa sebagai alat komunikasi yang digunakan oleh masyarakat dalam berkomunikasi merupakan praktek budaya, bahasa juga merupakan sebagai sumber daya budaya. Olehnya itu penggunaan bahasa pada penutur yang dijumpai di TN Babul Maros merepresentasikan budaya mereka.

Sebagaimana penggunaan pilihan bahasa TB bahasa Bugis (BB) yang dilakukan oleh penutur jika berkomunikasi dengan wisatawan local hal tersebut menandakan adanya kedekatan emosional dan kesamaan budaya partisipan. Begitu halnya dengan penggunaan pilihan bahasa TB BMM yang digunakan oleh penutur dalam berkomunikasi dengan wisatawan domestic khususnya yang berasal dari Sulawesi Selatan sendiri dimana BMM merupakan pilihan utama bagi partisipan. Penggunaan BMM biasanya diawali oleh mitra tutur maka TB BMM menjadi pilihan bahasa hingga diakhir satu etape percakapan. Hal tersebut menandakan bahwa mitra tutur mengirim signal dan symbol kedaerahan kepada penutur, juga sebagai upaya kedekatan yang dilakukan oleh mitra tutur kepada penutur agar komunikasi berjalan dengan baik. Selain hal tersebut komunikasi dengan TB BMM merupakan suatu ikatan kedaerahan dan ada kesamaan budaya partisipan. Mitra tutur yang melakukan hal ini merupakan dwibahasawan/mutibahasawan atau memiliki kompetensi linguistik dan kompetensi budaya yang baik. Dalam konteks situasi pada percakapan antara pramuwisata dan wisatawan di TN Babul Maros dapat digambarkan sebagai berikut;

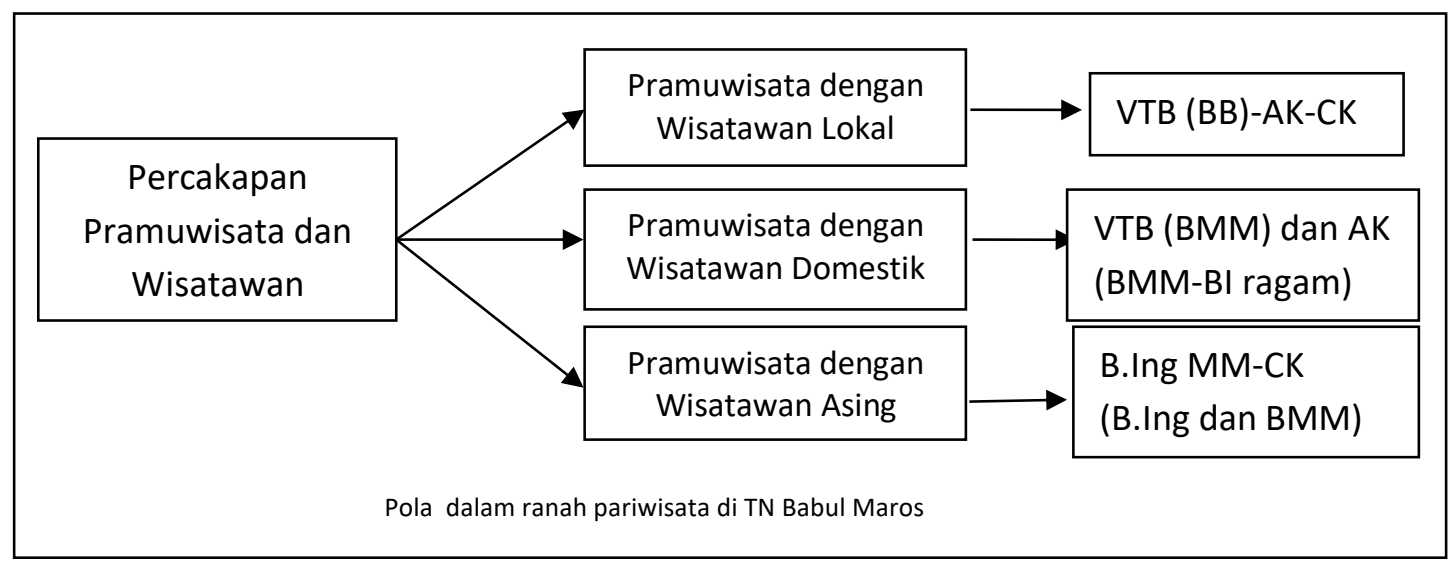

Diagram 1

\author{
$\mathrm{NB}$; \\ VTB : Variasi Tunggal bahasa \\ BB : Bahasa bugis \\ AK : Alih Kode Bahasa \\ CK : Campur kode bahasa \\ BMM : Bahasa Melayu Makassar \\ B.Ing MM: Bahasa Inggris dialek Melayu Makassar
}




\section{SASDAYA,}

Gadjah Mada Journal of Humanities, Vol. 5. No. 1, 2021

Berdasarkan kerangka pilihan bahasa di atas bahwa penggunaan AK dan CK kerapkali terjadi pada percakapan antara pramuwisata dengan wisatawan local. Begitu halnya dengan variasi tunggal bahasa bugis ditemukan dalam percakapan antara pramuwisata dan wisatawan local yang sudah saling akrab dan memiliki hubungan kekeluargaan. Penggunaan variasi tunggal bahasa dengan bMM ditemukan dalam situasi percakapan antara pramuwisata dengan wisatawan domestic yang bukan penutur bugis-Makassar (dalam area Sul-Sel). Sementara penggunaan variasi AK dari BMM ke B.I ragam formal terkadang ditemui pada situasi percakapan antara pramuwisata dan wisatawan domestic (wisatawan yang di luar Sul-Sel) ${ }^{8}$.

Untuk penggunaan bahasa Inggris terjadi pada situasi percakapan antara pramuwisata dengan wisatawan asing. adapun CK terjadi jika penutur menjelaskan sesuatu, atau terjadi interferensi atau bahwa mitra tutur sendiri yang melakukan CK sebagai upaya adaptasi linguistik dengan bahasa penutur.

Penggunaan variasi bahasa Inggris dialek Melayu Makassar (B.Ing MM) terjadi pada situasi percakapan antara pramuwisata dengan wisatawan asing. Dialek Melayu Makassar terus melekat bagi penutur meski mereka bukan suku Makassar, namun hal tersebut terjadi karena faktor adaptasi bahasa dari dialek yang sedang berlangsung di Kota Makassar. B.Ing MM pada dasarnya bukanlah sesuatu varian yang baru namun hanya merupakan penambahan akhiran tertentu atau sapaan biasa yang sering digunakan di dalam percakapan. Seperti pelajar bahasa Inggris yang merupakan penutur BB atau BM sehingga sering menggunakan dialek BMM maka dalam percakapan bahasa Inggris mereka akan nampak dialek Melayu Makassar. Sama halnya dengan situasi percakapan dalam ranah pariwisata yang terjadi di Bali baik pada kajian Beratha (1999) maupun kajian Budiarsa (2006) bahwa dalam kontak bahasa antara pramuwisata dan wisatawan yang sudah berlangsung lama tanpa adanya kesamaan budaya dari masing-masing partisipan sehingga melahirkan variasi bahasa sendiri maka dari itu Beratha menyebutnya sebagai pidgin.

Hal tersebut berbeda dengan variasi B.Ing MM yang ada di TN Babul Maros bahwa interaksi antara pramuwisata dengan wisatawan terbilang sedikit sehingga tidak melahirkan varian baru. Varian B.Ing MM hanya lahir dari budaya penutur etnis Bugis-Makassar yang sudah berlangsung lama. Menurut Holmes bahwa penyebab terjadinya variasi bahasa dipengaruhi atas dua faktor yaitu faktor internal dan faktor external. Adapun penyebab variasi bahasa Inggris atas dasar faktor internal atas variasi B.Ing MM yaitu terjadi karena pengaruh internal BB dan BM yang mempengaruhi penggunaan bahasa Inggris. Variasi secara internal ini menurut Richard (1973) (dalam Beratha, 2012) terdapat dua yaitu interlingual dan intralingual.

Seperti pada situasi percakapan yang ada di TN Babul Dalam interaksi tuturan SN (lokus 4) mencoba mengambil perhatian kepada kedua wisatawan tersebut dengan bertanya terkait makanan malam favorit kedua wisatawan tersebut sebagai referensi makanannya selama Indonesia. Situasi tuturan tersebut terjadi dalam suatu tuturan alami dengan tujuan menyambungkan komunikasi serta pelayanan kepada

${ }^{8}$ Wisawatan domestic yang berasal dari luar pulau Sulawesi seperti pulau Kalimantan, Jawa, Bali dan Sumatera. Jika pramwisata dari NTT, NTB dan Maluku masih menggunakan AK/ VTB BMM. 


\section{SASDAYA,}

Gadjah Mada Journal of Humanities, Vol. 5. No. 1, 2021

wisatawan yang dilakukan oleh masyarakat DTW. Sehingga mereka yang mendominasi percakapan dalam suatu perjamuan tersebut, karena lawan bicaranya adalah wisatawan asing yang tidak menguasai bahasa Indonesia dan pak D.Ras juga tidak menguasai bahasa Inggris sehingga si penutur D.Ras mencoba melakukan alih kode dalam bahasa bugis ke bahasa Indonesia dan dalam bahasa Indonesia ke Bahasa Inggris sambil dipertegas oleh SN. Dalam pembuka pembicaraan SN nampaknya mencoba mengambil perhatian BW terkait makanan favoritnya jika malam hari. Hal tersebut dilakukan SN demi mempersiapkan perjamuan makan malam sebentar atau keesokan harinya, atau bahkan sebagai referensi di dalam melakukan perjamuan kepada setiap tamu yang berkunjung dengan latar belakang budaya berbeda. Penggunaan B.Ing MM dalam situasi komunikasi di atas khususnya yang digunakan oleh penutur [D.Ras] kepada SN merupakan sebagai lingua franca lokal, sementara penutur [D.Ras] dengan wisatawan mancanegara yang dilakukan di meja makan merupakan interferensi.

\section{KESIMPULAN}

Percakapan dalam ranah pariwisata merupakan percakapan umum yang sama dengan percakapan lainnya. Namun hal yang berbeda yang ditemukan di TN Babul adalah adanya pilihan variasi BMM yang kerapkali digunakan oleh penutur baik sebagai alih kode maupun sebagai bahasa utama atau VTB. Variasi BMM tersebut sangat mempengaruhi penggunaan bahasa Inggris penutur, sehingga melahirkan varian bahasa Inggris baru yaitu varian Bahasa Inggris dialek Melayu Makassar atau B.Ing MM. dalam melangsungkan komunikasi dengan baik sangat dibutuhkan kompetensi linguistik serta kompetensi budaya agar dapat meminimalisir ketidaksinambungan komunikasi.

Situasi pilihan bahasa yang ada di kawasan taman nasional Babul Maros menggambarkan kompleksitas penggunaan bahasa masyarakat etnik bugis (meski kerapkali dinamai sebagai etnik bugis-Makassar). Dimana penggunaan bahasa baik TB BB, AK BB-BM, AK BB/BM-BMM, B.I-B.ING MM menjadi representasi budaya penutur. Sebagaimana dijelaskan oleh beberapa pakar sosio-linguistik seperti Abdul Chaer, Sumarsono dan lainnya bahwa penggunaan pilihan bahasa suatu masyarakat sangat identik dengan budaya penutur. begitu juga dengan pernyataan Duranti bahwa bahasa dalam praktek percakapan yang dilakukan oleh masyarakat merupakan sesuatu yang lahir secara alami di tengah masyarakat.

\section{DAFTAR PUSTAKA}

Agung, A., Wati, P., Simpen, I. W., \& Arnati, N. W. (2018). Kedwibahasaan Karyawan Pariwisata Kabupaten Gianyar, Bali. Jurnal Humanis Fakultas Ilmu Budaya UNUD Bali, 22(4), 1081-1088. https://doi.org/10.24843/JH.2018.v22.i04.p34

Apriliyani, N., \& Rokhman, F. (2016). Strategi Pemilihan Bahasa Pengusaha Industri di Kecamatan Ajibarang Kabupaten Banyumas. Seloka: Jurnal Pendidikan Bahasa Dan Sastra Indonesia, 5(2), 184-191.

Avraham, E. (2017). Changing the Conversation: How Developing Countries Handle the International Media During Disasters, Conflicts, and Tourism Crises. Journal of Information Policy, Penn State University Press, 7(May), 275-296. 


\section{SASDAYA,}

Gadjah Mada Journal of Humanities, Vol. 5. No. 1, 2021

Bachriani, Yassi, A. H., \& Rahman, F. (2018). A Comparative Study of Euphemism in English and Buginese: Pragmatic Stylistics. ELS Journal on Interdisciplinary Studies on Humanities, 1(4), 429-440. Retrieved from http

Beratha, N. L. S. (1999). Variasi Bahasa Inggris Pada Kawasan Pariwisata Di Bali. Humaniora, 11(3), 122-131. https://doi.org/10.22146/jh.v11i3.678

Bilingualism on display: The framing of Welsh and English in Welsh public spaces Author ( $s$ ): NIKOLAS COUPLAND Source: Language in Society, Vol . 41 , No . 1 ( February 2012 ), pp . 127 Published by: Cambridge University Press Stable URL: https://w. (2020). 41(1), 1-27.

Boxill, I., \& Hernandez, E. (2002). How Tourism Transforms Language: The Case Of Playa Del Carmen, Mexico. Social Economic Studies, Sir Arthur Lewis Institute of Social Economic Studies, 51(1), 47-60.

Budiarsa, M., \& Wijana, I. D. P. (2006). Penggunaan bahasa dalam ranah pariwisata di beberapa hotel di Kuta Kabupaten Badung Bali. [Yogyakarta]: Universitas Gadjah Mada.

Chaer, A., \& Agustina, L. (2004). Sosiolinguistik: perkenalan awal (Edisi Revisi).

Denvir, G. (2002). The Linguistic Implications of Mass Tourism in Gaeltacht Areas of Mass Tourism in Gaeltacht Areas. New Hibernia Review; University of St. Thomas, 6(3), 23-43.

Dörnyei, Z., \& Csizér, K. (2005). The effects of intercultural contact and tourism on language attitudes and language learning motivation. Journal of Language and Social Psychology, 24(4), 327-357. https://doi.org/10.1177/0261927X05281424

Duranti, A. (1997). Linguistic Anthropology. In International Encyclopedia of the Social \& Behavioral Sciences: Second Edition. https://doi.org/10.1016/B978-0-08-097086-8.53060-8

Fasold, R. W. (1984). The Sociolinguistics in Society. Retrieved from https://books.google.co.id/books?id=PAtFvgAACAAJ

Fishman, J. A. (1972). The Sociology of Language: An Interdisciplinary Social Science Approach to Language in Society.

Fox, R. (2008). English in tourism: a sociolinguistic perspective. Tourism and Hospitality Management, 14(1), 13-22.

Goebel, Z. (2007). An Ethnographic Study of Code Choice in Two Neighbourhoods of Indonesia An Ethnographic Study of Code Choice in Two Neighbourhoods of Indonesia *. Australian Journal of Linguistics; Routledge Taylor $\mathcal{E}$ Francis Group, 25(1), 85-107. https://doi.org/10.1080/07268600500113674

Grosjean, F. (2010). Language Mode and Langauge Choice. In Bilingual (pp. 39-50). Retrieved from http://www.jstor.com/stable/j.ctt13x0ft8.8\%0AJSTOR

Hanafia, N. (2011). Pemilihan Kode dalam Masyarakat Dwibahasa: Masyarakat Jawa di Daerah Jatibening Bekasi. Pendidikan Bahasa Dan Sastra, 10(1), 30-40.

Hasyim, Muhammad, Akhmar, A. M., Kuswarini, P., \& Masdiana. (2018). Pemahaman dan Penggunaan Variasi Bahasa Prancis Bidang Agrowisata bagi Stakeholder Pariwisata Di Makassar Sebagai Upaya Peningkatan Pelayanan Kepada Turis Mancanegara. Jurnal Ilmu Buaya, 6(2), 313-320. 


\section{SASDAYA,}

Gadjah Mada Journal of Humanities, Vol. 5. No. 1, 2021

Hasyim, Munira. (2008). Faktor Penentu Penggunaan Bahasa pada Masyarakat Tutur Makassar : Kajian Sosiolinguistik di Kabupaten Gowa. HUMANIORA UGM, 20(1), 75-88.

Hymes, D. (2013). Foundations in Sociolinguistics: An ethnographic approach. Retrieved from https://books.google.co.id/books?id=8c9SAQAAQBAJ

Khotimah, D. K. (n.d.). Pemilihan Kode Bahasa pada Masyarakat Tutur di Kelurahan Sukapura, Kecamatan Kiaracondong Kota Bandung (Kajian Sosiolinguistik). UPI.

Laiya, R. E. (2015). Pilihan Bahasa pada Masyarakat Multibahasa di Desa Botohilisorake Nias Selatan (Penelitian Etnografi pada Masyarakat Multibahasawan Nias, Indonesia dan Inggris). BAHTERA: Jurnal Pendidikan Bahasa Dan Sastra, 14(2), 156-167. https://doi.org/10.21009/bahtera.142.05

Mahsusi, J., Djatmika, \& Marmanto, S. (2017). Pemilihan Kode pada Mahasiswa Riau di Yogyakarta: Kajian Sosiolinguistik. dalam LINGUA, 14(2), 267-284.

Malini, N. L. N. S., Laksminy, N. L. P., \& Sulibra, I. N. K. (2018). Pilihan Bahasa Generasi Muda di Destinasi Wisata di Bali. Jurnal Kajian Bali, 08(12), 71-94.

Mardikantoro, H. B. (2012). Pilihan Bahasa Masyarakat Samin Dalam Ranah Keluarga. Humaniora, 24(3), 345-357. https://doi.org/10.22146/jh.v24i3.1376

Mohammad, A., \& Al-harahsheh, A. M. A. (2015). A Conversation Analysis of self-initiated repair structures in Jordanian Spoken Arabic. Discourse Studies; SAGE Publication, 17(4), 397-414.

Mondada, L. (2012). The dynamics of embodied participation and language choice in multilingual meetings. Language in Society; JSTOR, 41(2), 213-235.

Morgan, M. (2014). Speech Community. Cambridge University Press.

Muthmainnah, Y. (2008). Pemilihan Kode dalam Masyarakat Dwibahasa : Kajian Sosiolinguistik Pada Masyarakat Jawa Di Kota Bontang Kalimantan Timur. Universitas Diponegoro.

Niswa, L., \& M. Mukhlish. (2017). Pilihan Bahasa dalam Masyarakat Multilingual di Karimunjawa Jepara. Caraka, 3(2), 110-126.

Nursjam. (2011). Indonesian Code Mixing in Tourism Context. SAWERIGADING, 17(2), 179188.

Pelras, C. (1997). The Bugis (first edition). Blackwell Publisher.

Rusdiah. (2016). Code-Switching Serves a Euphemism. International Journal of Science and Research (IJSR), 5(1), 786-790.

Setyanto, A. (2014). Pentingnya Penguasaan Bahasa dan Budaya Asing Sebagai Pendukung Utama Sektor Pariwisata. Jurnal Pariwisata: FIB Universitas Brawijaya, 1(1), 1-12.

Suamba, I. M. S., Budiarsa, M., Suastra, I. M., \& Dhanawaty, N. M. (2020). Phonological Aspects of Korean Tourism Humour in Bali Indonesia. The International Journal of Social Sciences World; Growing Scholar Publishing, 2(01), 41-50.

Sudana, I. W. (2014). Penggunaan Bahasa Indonesia oleh Penutur Asing. dalam AKSARA, 26(2), 109-120. 


\section{SASDAYA,}

Gadjah Mada Journal of Humanities, Vol. 5. No. 1, 2021

Sudono, A. (2014). Wujud Kode Pilihan Bahasa Di Pasar Tradisional Kecamatan Winong, Kabupaten Pati. Widyariset, 17(1), 35-48.

Sugeha, A. Z. (2017). Variasi Pilihan Bahasa Pada Masyarakat di Kabupaten Probolinggo: Kajian Etnografis. Etnolingual, 1(1), 1-10. https://doi.org/10.1037/0022-3514.51.6.1173

Suktiningsih, W., \& Bumigora, U. (2017). Language choice among teenager ethnic sasak of mataram. RETORIKA: Jurnal Ilmu Bahasa, 3(2), 10-19. https://doi.org/10.22225/jr.3.2.334.

Sulastriana, E. (2017). Sikap Bahasa Dan Pemilihan Bahasa Mahasiswa Urban Di Ikip Pgri Pontianak. Jurnal Pendidikan Bahasa, 6(2), 258-270.

Tamrin. (2013). Pemilihan Bahasa dalam Ranah Keluarga: Studi Kasus Pemilihan Bahasa Buis oleh Etnis Bugis di kabupaten Donggala Sulawesi Tengah. Multilingual, XII(1), 145-160.

Thomas, C., \& Rustono. (2016). Akulturasi Budaya Dalam Pilihan Bahasa Pedagang Etnis Tionghoa Pada Ranah Perdagangan Di Kota Salatiga. Seloka - Jurnal Pendidikan Bahasa Dan Sastra Indonesia, 5(1), 39-47.

Wahab, L. A. (2015). Pilihan Bahasa pada Komunitas Tutur Pasar Baruga. Al-Izzah, 10(2), 149169.

Wardhani, P. (2018). Wujud Pilihan Bahasa Dalam Ranah Keluarga Pada Masyarakat Perumahan Di Kota Purbalingga. KREDO: Jurnal Ilmiah Bahasa Dan Sastra, 1(2), 91-105. https://doi.org/10.24176/kredo.v1i2.2147

Wardhaugh, R. (2006). An Introduction to Sociolinguistics. In Religion (FIFTH). https://doi.org/10.1353/lan.2003.0268

Widianto, E. (2016). Pilihan Bahasa dalam Interaksi Pembelajaran Bahasa Indonesia bagi Penutur Asing. Seloka: Jurnal Pendidikan Bahasa Dan Sastra Indonesia, 5(2), 124-135. 